\title{
Adapted cost-benefit analysis methodology for innovative railway services
}

\author{
Giuseppe Siciliano $^{1}$ (D) Francesco Barontini $^{1} \cdot$ Dewan Md Zahurul Islam $^{2}$ • \\ Thomas H. Zunder ${ }^{2} \cdot$ Stefan $_{\text {Mahler }}{ }^{3}$ - Ilaria Grossoni ${ }^{4}$
}

Received: 22 December 2015 / Accepted: 14 July 2016 / Published online: 7 September 2016

(C) The Author(s) 2016. This article is published with open access at SpringerLink.com

\begin{abstract}
Purpose This paper reviews and adapts the methodology "Guide on the methodology for carrying out cost-benefit analysis" prepared by the European Commission (EC). It is specifically tailored to the assessment of an innovative rail freight service, and its application in the context of a number of potential service areas (principally pan European) in Europe. The SPECTRUM service is an innovative rail freight concept for the transport of low density high value (LDHV) goods. Methods The methodology is primarily based on the "Guide to cost-benefit analysis of investment projects" of the European Commission. The cost definition takes input from a Life Cycle Cost analysis and applies a series of conversion factors. The benefits have been estimated considering the user's surplus, i.e. the difference between Generalised Logistic Costs (GLC) borne by transport/logistics operators (and more in general freight transport service users) when using the SPECTRUM service and GLC connected to "preshift" mode, i.e. road or traditional rail; and the difference in external costs generated by freight transport activities connected to externalities such as air pollution and climate change, noise, accidents, and other externalities (up- and down-stream
\end{abstract}

This article is part of Topical Collection on The Future of rail freight transport and logistics

Giuseppe Siciliano

giuseppe.siciliano@unibocconi.it

Certet-Università Bocconi, Milan, Italy

2 NewRail - Newcastle Centre for Railway Research, Newcastle University, Newcastle upon Tyne, NE1 7RU, UK

3 Railistics GmbH, Wiesbaden, DE, Germany

4 University of Huddersfield, Huddersfield, UK processes, nature and landscape, biodiversity losses, soil and water pollution, congestion).

Results The adapted methodology has proven capable of representing the multiple effects resulting from the theoretical introduction of an innovative rail service in the freight transport sector - accounting for the differential impacts compared to the baseline scenario solutions. The logical articulation of the analysis is flexible; two specific estimation schemes (the estimation of ad hoc unit parameters for the external costs and ad hoc approach for using GLC as proxies of users' surplus in a scenario where the introduction of the innovative service modifies the modal split of freight transport between different solutions) can be applied to other territorial contexts. It may also be used to evaluate other types of freight transport services, provided that some unit data can be retrieved, which pertain to site-specific cost of infrastructures, average speeds and rates of different transport solutions, costs of personnel and other operating costs.

Keywords Cost-benefit analysis $\cdot$ Rail transport $\cdot$ Freight transport

\section{Introduction}

Over the last few decades there has been a significant growth in freight transport, most of which is served by road freight transport in Europe. In contrast, the share of rail freight transport has either declined or remained stagnant with an exception in a few countries where there is a slight growth in rail freight transport. Apart from the dynamic nature of the road service offering, an important reason of the dominance of road hauliers in the freight transport sector is linked to their ability to deliver certain types of cargo. Types of cargo which have significantly changed from manufacturing inputs, to finished and semi-finished products. These types of cargo require 
faster, more reliable, door-to-door services and where rail traditionally has an unfavourable position. Road freight transport is the major source of greenhouse gas (ghg) emission, in contrast rail freight transport is seen as an environment friendly transport mode option. The European Commission (EC) at the central level and many member states (e.g. France, Germany, and the UK) at the national level have been trying to encourage the higher usage of rail freight transport (i.e. modal shift in favour of rail) to reduce the environmental effects from the transport sector and reduce road congestion, in particular peak hours [11]. This is demonstrated through the funding of various projects such as; RETRACK -"RETRACK: REorganisation of Transport networks by advanced RAil freight Concepts." [22]; CREAM - "Technical and operational innovations implemented on a European rail freight corridor) [14], under the sixth Framework Programme [7], and SPECTRUM - "Solutions and Processes to Enhance the Competitiveness of freight Transport by Rail in Unexploited Markets" under seventh Framework Programme [24]. The scope of the research and demonstration under the RETRACK and CREAM projects concerned all cargo types. In contrast the scope of the research and demonstration in the SPECTRUM project focused specifically on the market of low-density high value (LDHV) goods. The research in SPECTRUM project realised at the outset that to achieve modal shift from road it is important to offer a comparable service to road in terms of cost and transhipment time. This is crucial in the sense that the European rail freight market is ostensibly a free market where, since 1 January 2007 and competition in a competitive environment is an indisputable need for the building of an efficient freight transport sector [5]. With this context in mind, the research in the SPECTRUM project explored four service areas in Europe. It is a fact that to meet the continuous growth, the volume of freight transport and its external costs are rising [4]. The external costs vary significantly between modes. It is important that the fullsocio-environmental costs of competing transport mode options are accounted for [25].

This research paper firstly explores the currently accepted and widely applied method of assessing the benefits of a project against its associated costs, known as Cost-Benefit Analysis (CBA). By reviewing the "Guide to Cost Benefit Analysis of Investment Projects" prepared by the European Commission (EC), the paper presents an adaptation of this methodology, specifically tailored to the assessment of an innovative rail freight service, and its application in the context of a number of potential service areas (principally pan European) in Europe.

The EC Guideline was developed for the Commission services in late 1990s to help them judge the quality of projects proposed for financing by Member State, and it rapidly achieved a wide circulation so that later versions were aimed not only at EC services but also at staff of financial institutions, consultants and analysts. The Guide is therefore a contribution to a shared European-wide evaluation culture in the field of project appraisal.

The methods in this paper, and some additional parameters, are presented as options to implement the current EC method of CBA for a specific type of project. This research was conducted as part of the SPECTRUM project that aimed to realize an innovative rail freight concept for the transportation of lowdensity high value (LDHV) goods, which are traditionally considered non-rail cargo and predominantly handled by road transport [15, 24].

Every time an investment decision has to be taken a weighting of costs against benefits is necessary, and some form of calculation over time is needed to compare the former with the latter when they accrue in different years [16]. Cost Benefit Analysis (CBA) is a widely applied tool for identifying and monetizing the impacts of an investment decision in order to determine the project costs and benefits; the aggregated results can support conclusions on whether the project is desirable and worth implementing [26]. The difference between this and a Financial Analysis is that the latter considers the "private" point (such as profit and loss against an investment decision) of view of the subjects who run the project/ operations (and/or make it commercially viable for a company). CBA makes an assessment from the social perspective (i.e. social cost and benefits) of the "public" in a country or region by comparing differential costs and benefits that may include non-market elements (e.g. externalities) and nonquantifiable benefits, and which are borne or taken by the community.

Hilmola [13] suggests that although CBA is the most frequently used method of evaluating ex ante the costs and benefits of rail infrastructure investment projects; there are doubts about the accuracy of this method as many relevant aspects are ignored. Similar concern is raised by other experts as well. For example, Mackie [18] opines that it is: 'a controversial tool, generating accusations of unacceptable principle, improper application, inadequate evidence base and bias'. Also Mackie and Preston [19] identified as many as twentyone errors and bias in the application of the CBA tool for appraisal of projects. With this criticism in mind, the objective of the paper is to present the specific methodological approaches elaborated for the estimation of some of the elements needed for the CBA application.

The SPECTRUM solution is defined by the following elements:

- Loading unit: 20'/40' ISO containers including reefers

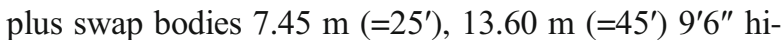
cube Euro-container module (equivalent to a standard triaxle semi-trailer in terms of cargo volume and weight capability), including reefer models of aforementioned standard units. 
- Freight Handling: Vehicle mounted horizontal transhipment - containermover 3000. Designated terminals are not required

- Goods Type: LDHV: Containerised, refrigerated, palletized

- Capacity management: Freight vehicles specifically carrying LDHV goods are assigned equal priority to passenger services. SPECTRUM trains/rail vehicles are able to accelerate and brake at passenger train equivalent speeds to maximise the use of available train paths. SPECTRUM train is able to use passenger specific lines and routes including loops/sidings.

- Operational pattern: See par. 3.2.2. Resourcing: Crew rostering will aim to maximise train/wagon productivity. Available systems to roster crews should be adopted. These ensure personnel with the right qualifications and skill sets are available to drive the trains with no loss of time awaiting crew arrival and thereby to maximise the train's commercial capability.

- Condition monitoring (cargo): Cargo condition monitoring will include temperature monitoring of goods.

- Tracking and tracing: Train location in real time will be available to the operator for purposes of train planning, duty cycle rostering etc. In the event of disruption systems will inform shippers/receivers directly of any problem and indicate a revised estimated time of arrival (ETA). Shippers should be able to identify the location of their cargo/container/swap body/trailer in real time independently of the train operator and infrastructure manager.

- Wagon type: Un-powered flat platform wagons to accommodate hi-cube containers. The wagon will be modular to be able to accommodate a range of different end applications with modifications to accept containermover 3000 technology. Common chassis/frame, bogies, auxiliaries, braking systems and pipework/wiring should be mandatory. This might also include train control loops for any push-pull applications.

- Vehicle performance: The train will have speed characteristics similar to passenger vehicles this includes; acceleration $(0.5 \mathrm{~m} / \mathrm{s} 2)$, maximum speed $(140-160 \mathrm{~km} / \mathrm{h})$, average speed $(120 \mathrm{~km} / \mathrm{h})$ and service braking/deceleration $(0.7 \mathrm{~m} / \mathrm{s} 2)$. Axle load of $17 \mathrm{t}$.

- Vehicle configuration: Shorter loco hauled fixed formation (unbreakable) freight trains ( $\max 10-15$ vehicles).

- Condition monitoring (vehicle): Monitoring of oscillations/vibrations in the suspension system in relation to the ride quality for LDHV goods. Wagons will have individual condition monitoring for technical wellbeing including bearing temperatures.

- Traction: Electric loco with provision for last mile, terminal operations and off line (no electrical power supply) operations using diesel or battery power. For the purposes of interoperability the locomotive will have the capability to operate on a number of European voltages.

- Maintenance: SPECTRUM vehicles will be reliable and designed for extended operations with minimal routine maintenance. The remote condition monitoring will assist with the achievement of this and minimise in transit failures and failures with no warning. The design, materials, engineering and maintenance regime will reflect a commercial requirement for extended periods in operation with limited time allowed for this activity. The vehicles/ trains will need to maximise their in service time. Maintenance and checks where required will be undertaken as the trains/wagons are being loaded or stripped. This could also apply to any fuel replenishment for any train requiring diesel fuel. Both maintenance and re-fuelling will come to the train rather than losing production time.

\section{Methodology}

The economic analysis (CBA) appraises the project's contribution to the economic welfare of the region or country [21]. It is made on behalf of the whole of society instead of just the owners of the infrastructure or the transport project, as in the financial analysis. The rationale underpinning economic evaluation is that project inputs should be valued at their opportunity cost and outputs at consumers' willingness to pay. It should be noted that the opportunity cost does not necessarily correspond to the observed financial cost; similarly, willingness to pay is not always correctly revealed by observed market prices, which may be distorted or even absent. Economic analysis is undertaken from the point of view of society.

The financial analysis cash flows are taken as the starting point of the economic analysis. In determining the economic performance indicators, some adjustments need to be made.

- Fiscal corrections: indirect taxes (e.g. VAT), subsidies and pure transfer payments (e.g. social security payments) must be deducted. However, prices should be gross of direct taxes.

- Benefits from the reduction of externalities: some impacts may be generated that spill over from the project to other economic agents without any compensation. These effects can either be negative (a new road increasing pollution levels) or positive (a new railway reducing traffic congestion on an alternative road link). As, by definition, externalities occur without monetary compensation, these are not present in the financial analysis and therefore need to be estimated and valued.

- Time savings: time benefits often represent the most important element of a transport project benefits. CBA considers time savings as a benefit, calculated on the basis of the estimation of the value of time for goods shifted from road to rail. 
- Safety improvements: safety improvements and accident reduction, for modernisation projects, for both users and staff, have to be assessed and calculated as benefits of the project.

- From market to accounting (shadow) prices: besides fiscal distortions and externalities, other factors can drive prices away from a competitive market (i.e. efficient) equilibrium: monopoly regimes, trade barriers, labour regulation, incomplete information, etc. In all such cases, observed market prices are misleading; accounting (shadow) prices need to be used. Accounting prices are computed by applying conversion factors to the financial prices.

Once the stream of economic costs and benefits is estimated, the standard discount factor (DCF) methodology is applied, ensuring a social discount rate is used. The following economic performance indicators can be determined for the project:

- Economic net present value (ENPV): should be greater than zero for the project to be desirable from an economic standpoint. From a mathematical point of view ENPV is

$$
\mathrm{ENPV}=\sum_{\mathrm{t}=0}^{\mathrm{t}=\mathrm{n}} \frac{\left(\mathrm{B}_{\mathrm{t}}-\mathrm{C}_{\mathrm{t}}\right)}{(1+\mathrm{r})^{\mathrm{t}}}
$$

Where:

$E N P V=$ Economic Net Present Value.

$\mathrm{B}_{t}=$ Benefits (inflows) in year $\mathrm{t}$.

$\mathrm{C}_{t}=$ Costs (outflows) in year $\mathrm{t}$,

$r=$ Discount rate

- Economic rate of return (ERR): should be greater than the social discount rate. ERR is calculated by solving with the process of trial-error the following formula and the meaning of letters is the same here as in NPV formula.

$\sum_{t=0}^{t=n} \frac{\left(B_{t}-C_{t}\right)}{(1+E R R)^{t}}=0$

When ERR is less than the discount rate (cost of capital) the proposed alternative should be rejected. We can summarize the decision rule as:

When ERR $>$ r, then accept.

When $\mathrm{ERR}<\mathrm{r}$, then reject

- Benefit/Cost ratio (B/C): should be greater than one. Another form of the ENPV criterion is called Benefit-
Cost Ratio (BCR), which is, in effect, another way of comparing the present value of the proposed alternatives costs with benefits. Instead of calculating the ENPV by subtracting present value of Costs from the present value of Benefits we divide present value of Costs into the present value of Benefits. In mathematical terms:

$\mathrm{BCR}=\frac{\sum_{\mathrm{t}=0}^{\mathrm{t}=\mathrm{n}} \frac{\left(\mathrm{B}_{\mathrm{t}}\right)}{(1+\mathrm{r})^{\mathrm{t}}}}{\sum_{\mathrm{t}=0}^{\mathrm{n}=0} \frac{\left(\mathrm{C}_{\mathrm{t}}\right)}{(1+\mathrm{r})^{\mathrm{t}}}}$

If this ration is equal to or greater than unity, then accept the alternative. If it is less, then reject the alternative. It should be clear that when:

$\mathrm{NPV}=0$, then $\mathrm{BCR}=1$ and,

$\mathrm{NPV}<0$, then $\mathrm{BCR}<1$.

\subsection{Definition of specific elements of the CBA}

As emerges from the previous paragraphs the first elements that have to be set for the analysis are:

- Time horizon: time horizon must be consistent with the economic life of the main assets. Although the investment horizon is often indefinite, in project analysis it is convenient to assume reaching a point in the future when all the assets and all the liabilities are virtually liquidated simultaneously. Conceptually, it is at that point that one can cost up the accounts and verify whether the investment was a success. As recommended by the "Guide to cost-benefit analysis of investment projects" of the European Commission the analysis will adopt as reference time horizon (years) for SPECTRUM (as a railway project) 30 years. ${ }^{1}$ Another necessary step is to set the base year of the analysis which often depends on availability of data - preferably as recent as possible. Hence, considering a reasonable time lapse to implement the SPECTRUM solution, the base year of the analysis is set at 2016 for the start of the operational phase.

- Discount rate: the discount rate that the analysis will adopt derives from the "Guide to cost-benefit analysis of investment projects" of the Directorate General Regional Policy of the European Commission, and is fixed at $3.5 \% .^{2}$

- Geographical scope: since the SPECTRUM solutions are elaborated, supported and fostered within the framework

\footnotetext{
${ }^{1}$ European Commission [10]

${ }^{2}$ European Commission [10]
} 
of the EC transport policy, the collectivity which costs and benefits should refer to, is the EU collectivity. The geographical scope, in principle, is therefore the European territory. Indeed, the rail services based on SPECTRUM solutions have been shown ${ }^{3}$ to have the potential to be conveniently implemented on certain corridors, whereas the current and foreseen market conditions in other parts of the European transport networks do not allow to realistically assume the possibility to expand SPECTRUM services. Therefore, the costs and benefits of the SPECTRUM solutions will be assessed at the service area level. In other words, the reference "universe" into which unit costs and revenues and unit benefits will be expanded is the one that includes the corridors previously defined, and we assume that such scope coincides with the magnitude of costs and benefits at the EU level. Hence, the analysis will cover 3 service areas i.e. a Swiss route (Service Area 1: Daillens - Chur, via Zurich), a Scandinavian route (Service Area 2: Hallsberg - Malmö - Copenhagen), and a route between Italy and France (Service Area 3: Turin - Lyon).

\subsubsection{Costs}

The first logical step in the FA and CBA is the estimation of how large the total investment cost will be. The cost of a transportation project in economic terms is the value of the resources that must be consumed to bring the project about. What must be estimated is the total value of the implementation costs and any additional operating costs. It is important to note that the CBA does not distinguish between who incurs the cost but rather aims to include any and all costs that are involved in bringing about the project. The implementation of SPECTRUM solutions will require investment costs not only in terms of equipment and rolling stock, but also - at a macro level - investment for adapting rail infrastructure to improved train standards, necessary to attract LDHV traffic to rail. Hence three cost categories are defined (Fig. 1).

- Infrastructural costs: infrastructural investments concern:

1. The investments on the lines (necessary adjustments of the rail network or parts of it): needs to be highlighted, however, such an exercise overcomes the scope of the SPECTRUM project because it is assumed that major bottlenecks and infrastructural needs will be addressed anyway and because the "SPECTRUM" train, in principle, capable of running in the current network and in the

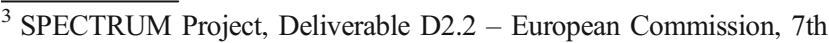
Framework Program, [23].
}

existing rail context. Therefore, no investment costs on the lines are considered, both in the FA and in the CBA. The investments in terminals (necessary for enabling the operation of SPECTRUM trains in an efficient manner): it was pointed out how the innovative concepts of SPECTRUM trains, could not exploit their potential in making rail freight supply chain more efficient if terminals (e.g. in a selected route/corridor) do not adapt their layout and organization. Such investments mostly derive from the increased speed of SPECTRUM trains, which will imply an improvement in transfer times; in other words the duration of the actual train operation itself, so with a higher speed the train takes less time to reach its destination. In order not to lose such advantage during terminal operations, it will be necessary to enable (i) fast access, (ii) fast railway operations, (iii) short transhipment times. In WP2 investments in terminals are defined as investments in tracks and switches, in pavement area, in buildings and local infrastructures.

- Development costs: these items derive from the technical definition of the SPECTRUM concepts and they define the overall expenditure for the physical implementation of the transportation tools. In practical terms, development costs regard the physical construction of the SPECTRUM train, and concern the engineering materials, needed to realize the service. In fact specific engineering tools will be applied to:

- The material of the body of the vehicle;

- The propulsion of the vehicle;

- The running gear and suspension system;

- The condition monitoring;

- The electrical systems and coupling;

- Tracking and tracing systems.

- Operating costs: the operating costs comprise all the data on the disbursements foreseen for the purchase of goods and services, which are not of an investment nature since they are consumed within each accounting period. They include the direct production costs (consumption of materials and services, personnel, maintenance, general production costs). At this stage, because of the early phase of the implementation of the project, administrative and general expenditures, sales and distribution expenditures are not considered.

Since the objective of CBA is to appraise the social value of the investment, and observed prices, as set by markets or by governments, sometimes do not provide a good measure of the social opportunity cost of inputs and outputs, they are converted into shadow prices, that better reflect the social 


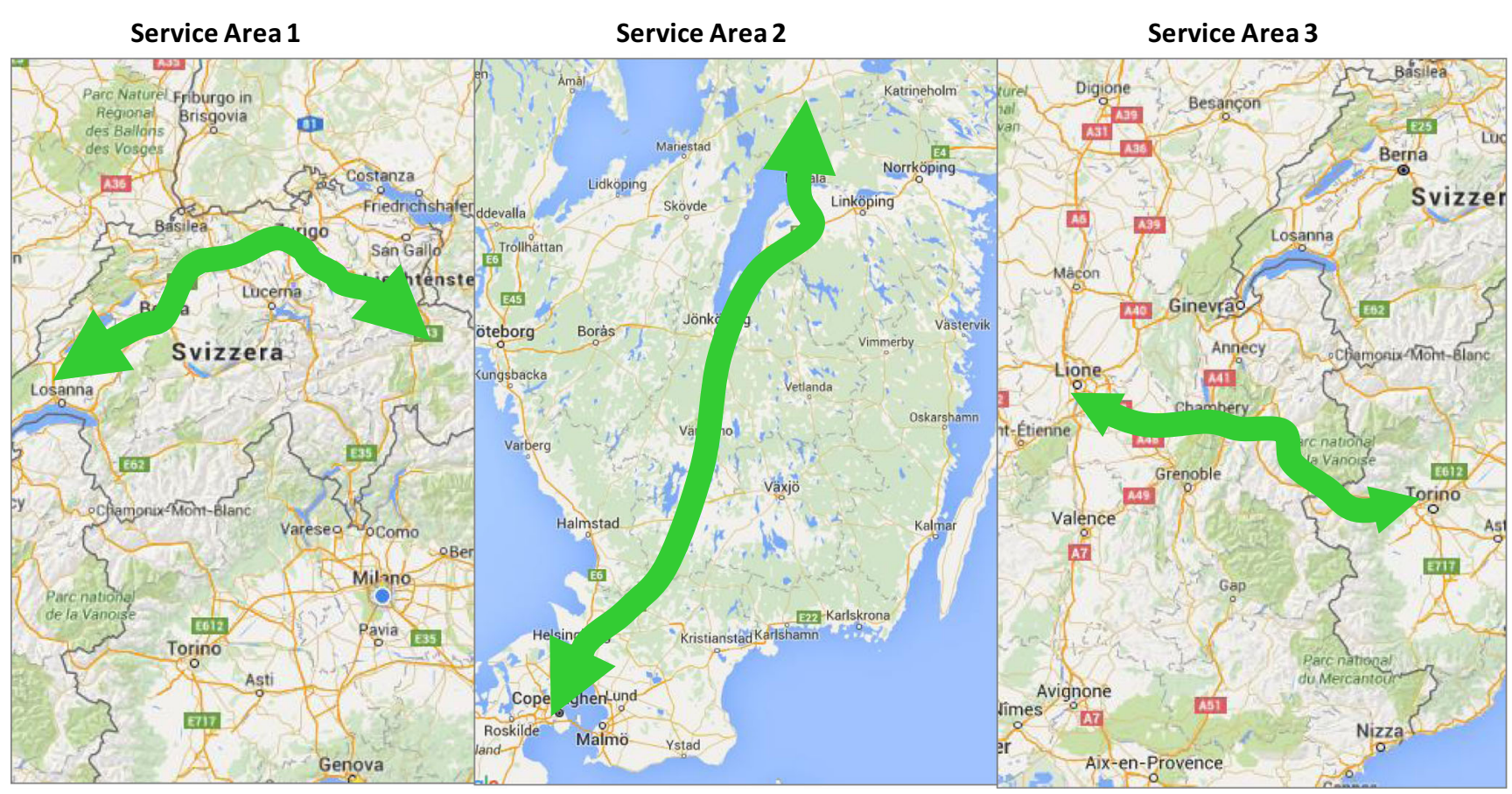

Fig. 1 Map of the SPECTRUM Service Areas

opportunity cost of the good. Within the "Guide to cost benefit analysis of investment projects" the European Commission has developed a set of conversion factors for the appraisal of all railway major projects that provide the values that have to be applied to some items, as equipment, labor, freights, expropriations, administrative costs, maintenance, extraordinary maintenance. ${ }^{4}$ Table 1 shows the list of defined cost items and the corresponding conversion factors.

\subsubsection{Benefits}

The activation of the SPECTRUM rail service, by improving the competitiveness of rail freight will generate a modal shift from road to rail, which is a policy objective set the European Commission's Transport White Paper 2011 [11]. Shippers and forwarders will find it more convenient to ship their goods via services that involve the new rail route. While in the financial analysis this effect is translated into the deriving tariff revenues, the impact in terms of economic benefits for the community can be quantified by means of the user's surplus concept, that is the differential benefit to use the new solution rather than the baseline one. In order to measure this, the Generalized Logistics Cost is calculated for all the involved scenarios. GLC is the sum of all costs borne by a user in order to get a service and include monetary tariffs and the value of time and is calculated in terms of Euro per tonne.

Some assumptions have been made to assess GLCs of the different service areas:

\footnotetext{
${ }^{4}$ European Commission [10]
}

- Average unit cost estimated from past studies and reflects the fact that regular rail costs less than road.

- Distances are expressed for one direction only and the calculation assumes, in consultation with experts in the field that each pre- and post-haulage leg is on average $75 \mathrm{~km}$ long. Since one of the main advantages of SPECTRUM is the multi-stop concept which brings

Table 1 Cost items of the SPECTRUM Service and conversion factors

\begin{tabular}{lc}
\hline Cost item & Conversion factor \\
\hline Investment costs & \\
Investment in terminals - Infrastructure & 0,867 \\
Investment in terminals - Equipment & 0,918 \\
Development costs & \\
Investment per E-traction & 0,918 \\
Investment for Steering Cap & 0,918 \\
Operating costs & \\
Cost of wagons (incl. Maintenance) & 0,918 \\
Personnel costs & 0,747 \\
Energy costs & 1,0 \\
Shunting costs & 0,777 \\
Transhipment costs & 0,867 \\
Maintenance costs (traction units) & 0,835 \\
Overhaul costs (traction units) & 0,835 \\
Insurance costs (traction units) & 1,00 \\
Maintenance costs (terminal infrastructure) & 0,835 \\
Maintenance costs (terminal equipment) & 0,835 \\
\hline
\end{tabular}

Source: European Commission [10] 
freight closer to the service, the average pre-/post-haulage distance is shorter than the one assumed for the regular services $(100 \mathrm{~km}){ }^{5}$

- The Values of Time are based on [12] figures (site specific), and take into account inflation. According to HEATCO, the average VoT of road (commodities transported by road) is higher than the VoT of rail (commodities transported by rail); the SPECTRUM train will, due to its shorter door to door time and higher reliability, attract some commodities from road. It is likely that the VoT of these commodities are not representative of the average of all commodities that are transported by road since in that case most of the road transport will shift to the SPECTRUM train. It is also likely that the value of SPECTRUM commodities is not the average of the commodities that are transported by regular rail, since in that case it is likely that these commodities would not change service. A reasonable assumption is to take the average of the VoTs of road and rail as a proxy of the VoT of SPECTRUM commodities.

- Average speed figures are based on industrial experience, and for the SPECTRUM scenario it is based on design specifications.

GLC have been calculated for the all-road, regular rail and SPECTRUM service.

Three types of SPECTRUM user benefits are then estimated (in terms of Euro per ton):

i) Benefits for SPECTRUM users who use regular rail in the baseline scenario (existing rail traffic): this is calculated according to the rule of the half ${ }^{6}$ as $\left(\mathrm{GLC}_{\mathrm{SR}}-\right.$ $\left(\mathrm{GLC}_{\mathrm{RR}}\right.$ ) / 2. In case it is positive (i.e. SPECTRUM costs more than regular rail) it is assumed to represent a minimum differential internal benefit which users obtain from the SPECTRUM service, so that this compensates its higher monetary and time costs and makes them choose such solution despite higher costs. In case it is negative, it is also considered in absolute terms in that it represents the net monetary and time cost advantage of SPECTRUM, in addition to an internal benefit which in this case cannot be quantified.

ii) Benefits for SPECTRUM users who use the all road solution in the baseline scenario (shifted traffic): $\mathrm{GLC}_{\mathrm{SR}}-\mathrm{GLC}_{\mathrm{AR}}$. Similarly to the previous type of benefit, the difference with the GLC in the all road scenario can be positive or negative. In case it is negative, it is considered in absolute terms in that it represents a direct "saving" for the user; in case it is positive (i.e. SPECTRUM costs more than all road) it is also

\footnotetext{
$\overline{5}$ Assumptions validated by railway and logistics experts within the SPECTRUM consortium.

${ }^{6}$ European Commission [10]
}

considered in absolute terms in that it represents the minimum differential internal benefit which users obtain from the SPECTRUM service, so that this compensates its higher monetary and time costs and makes them choose such solution despite higher costs.

iii) Benefits for SPECTRUM users who do not use transport services in the baseline scenario (new traffic): $\mathrm{GLC}_{\mathrm{SR}}$. The rationale here is that users, unwilling to buy transport services before, are now using the SPECTRUM service despite incurring in its GLC therefore, the internal benefit they get from using this service is at least equal to the GLC.

This approach has been conceived in order to take into account not only the cases where the GLC decreases (which is assumed to be true by default by most literature - e.g. $[6,8]$ ) but also the cases in which other "soft" factors, that users include in their transport decisions, may impact the effectiveness of the new service despite a higher GLC. In other words, even when the GLC of the new solutions turns out to be higher, users may decide to use a new solutions because of factors different from tariffs and time, and in such cases the difference between $\mathrm{GLC}_{0}$ and $\mathrm{GLC}_{1}$ is considered the minimum monetary quantification of the residual factors (Tables 2 , $3,4,5,6,7,8,9$ and 10).

The following table splits the traffic results of the estimation model (2030 and 2044, the last year of the time horizon) into existing rail traffic, shifted traffic and new traffic. ${ }^{7}$

Some other impacts may be generated that spill over from the project to other economic agents without any compensation. These effects can either be negative (a new road increasing pollution levels) or positive (a new railway reducing traffic congestion on an alternative road link). As, by definition, externalities occur without monetary compensation, these are not present in the financial analysis and therefore need to be estimated and valued.

In the case of SPECTRUM, the introduction of innovative rail services generates a modal shift from road (an also attracts demand from the regular rail services), with deriving implications in terms of reduction of external costs.

10 categories of externalities are identified by the "Handbook on estimation of external costs in the transport sector" [20]. The advancements brought forth by the SPECTRUM solution, in fact, derive from technologies that involve wagon type, vehicle configuration, vehicle performance, condition monitoring and transhipment operation. The panel of experts in SPECTRUM have assessed that such solutions positively impact some of the externalities categories (namely air pollution and climate change, noise and accidents) (graphically displayed in the left side of Fig. 2),

\footnotetext{
${ }^{7}$ Figures taken from SPECTRUM Deliverable D4.1 and resulting from the application of the TRANSTOOLS model.
} 
Table 2 Estimation of GLCs for service area 1

\begin{tabular}{|c|c|c|c|}
\hline & $\operatorname{ALL} \operatorname{ROAD}\left(\mathrm{GLC}_{\mathrm{AR}}\right)$ & REGULAR RAIL $\left(\mathrm{GLC}_{\mathrm{RR}}\right)$ & $\begin{array}{l}\text { SPECTRUM RAIL } \\
\left(\mathrm{GLC}_{\mathrm{SR}}\right)\end{array}$ \\
\hline A) Euro per tkm ${ }^{\mathrm{a}}$ & 0.09 & 0.05 & 0.07 \\
\hline B) Distance $(\mathrm{km})^{\mathrm{b}}$ & 530 & 530 & 480 \\
\hline C) Fare per ton $=A * B$ & 43.7 & 30.8 & 35.9 \\
\hline D) Unit VoT (Euro per tkm) ${ }^{\mathrm{c}}$ & 2.81 & & \\
\hline E) Average speed $(\mathrm{Km} / \mathrm{h})^{\mathrm{d}}$ & 80 & 60 & 82 \\
\hline F) Transport time (hours) & 6.6 & 14.0 & 11.9 \\
\hline of which: Pre + post haulage ${ }^{\mathrm{e}}$ & 0 & 2.5 & 1.9 \\
\hline Main haulage $\mathrm{f}^{\mathrm{f}}$ & 6.6 & 5.5 & 4.0 \\
\hline Stops $^{\mathrm{h}}$ & 0 & 6.0 & 6.0 \\
\hline G) VoT per Ton $=\mathrm{D} * \mathrm{~F}$ & 18.6 & 39.4 & 33.5 \\
\hline $\mathrm{GLC}($ Euro per ton $)=\mathrm{C}+\mathrm{G}$ & 62.3 & 70.2 & 69.4 \\
\hline
\end{tabular}

Sources: Please see footnotes (6 to 12)

${ }^{a}$ Assumptions validated by railway and logistics experts within the SPECTRUM consortium

${ }^{\mathrm{b}}$ Based on public routing software calculation

${ }^{\mathrm{c}}$ Estimations based on figures from HEATCO [12]

${ }^{d}$ Assumptions validated by railway and logistics experts within the SPECTRUM consortium

${ }^{\mathrm{e}}$ Calculated basing on the average speed and the distance

${ }^{\mathrm{f}}$ Calculated basing on the average speed and the distance

${ }^{\mathrm{h}} \mathrm{hAn}$ average $2 \mathrm{~h}$ per stop is assumed therefore specific dedicated analyses have been carried out in order to estimated the unit parameters. For the other six out of ten categories (Up- and down-stream processes, Nature and landscape, Biodiversity losses, Soil and water pollution, Urban effects, Congestion) the usual rail parameters have been used for the comparison vs the all road solutions (graphically displayed in the right side of Fig. 2).

For the calculation of external costs of air pollution two different approaches can be used, the bottom-up-approach (or Impact Pathway Approach IPA) and the top-down-
Table 3 Estimation of GLCs for service area 2

\begin{tabular}{|c|c|c|c|}
\hline & All $\operatorname{road}\left(\mathrm{GLC}_{\mathrm{AR}}\right)$ & Regular rail $\left(\mathrm{GLC}_{\mathrm{RR}}\right)$ & SPECTRUM rail $\left(\mathrm{GLC}_{\mathrm{SR}}\right)$ \\
\hline A) Euro per tkm ${ }^{\mathrm{a}}$ & 0.09 & 0.05 & 0.07 \\
\hline B) Distance $(\mathrm{km})^{\mathrm{b}}$ & 874 & 874 & 824 \\
\hline C) Fare per ton $=A * B$ & 74.9 & 48.7 & 59.2 \\
\hline D) Unit VoT (Euro per tkm) ${ }^{\mathrm{c}}$ & & 2,99 & \\
\hline E) Average speed $(\mathrm{Km} / \mathrm{h})^{\mathrm{d}}$ & 80 & 60 & 100 \\
\hline F) Transport time (hours) & 10.9 & 23.7 & 18.6 \\
\hline of which: Pre + post haulage ${ }^{\mathrm{e}}$ & 0 & 2.5 & 1.9 \\
\hline Main haulage $\mathrm{f}^{\mathrm{f}}$ & 10.9 & 11.2 & 6.7 \\
\hline Stops $^{\mathrm{g}}$ & 0 & 10.0 & 10.0 \\
\hline G) VoT per Ton $=\mathrm{D} * \mathrm{~F}$ & 32.6 & 70.9 & 55.6 \\
\hline GLC $($ Euro per ton $)=\mathrm{C}+\mathrm{G}$ & 107.6 & 119.6 & 114.8 \\
\hline
\end{tabular}

Sources: Please see footnotes (13 to 19)

${ }^{a}$ Assumptions validated by railway and logistics experts within the SPECTRUM consortium

${ }^{\mathrm{b}}$ Based on public routing software calculation

${ }^{\mathrm{c}}$ Estimations based on figures from HEATCO [12]

${ }^{\mathrm{d}}$ Assumptions validated by railway and logistics experts within the SPECTRUM consortium.

${ }^{\mathrm{e}}$ Calculated basing on the average speed and the distance

${ }^{\mathrm{f}}$ Calculated basing on the average speed and the distance

${ }^{\mathrm{g}}$ An average $2 \mathrm{~h}$ per stop is assumed 
Table 4 Estimation of GLCs for Service area 3

\begin{tabular}{|c|c|c|c|}
\hline & All $\operatorname{road}\left(\mathrm{GLC}_{\mathrm{AR}}\right)$ & Regular rail $\left(\mathrm{GLC}_{\mathrm{RR}}\right)$ & SPECTRUM rail $\left(\mathrm{GLC}_{\mathrm{SR}}\right)$ \\
\hline A) Euro per tkm ${ }^{\mathrm{a}}$ & 0.09 & 0.05 & 0.07 \\
\hline B) Distance $(\mathrm{km})^{\mathrm{b}}$ & 545 & 545 & 495 \\
\hline C) Fare per ton $=A * B$ & 45.1 & 31.6 & 36.9 \\
\hline D) Unit VoT (Euro per tkm) ${ }^{\mathrm{c}}$ & 2.77 & & \\
\hline E) Average speed $(\mathrm{Km} / \mathrm{h})^{\mathrm{d}}$ & 80 & 60 & 100 \\
\hline F) Transport time (hours) & 6.8 & 12.3 & 9.3 \\
\hline of which: Pre + post haulage $\mathrm{e}^{\mathrm{e}}$ & 0 & 2.5 & 1.9 \\
\hline Main haulage $\mathrm{f}^{\mathrm{f}}$ & 6.8 & 5.8 & 3.5 \\
\hline Stops ${ }^{\mathrm{g}}$ & 0 & 4.0 & 4.0 \\
\hline G) VoT per Ton = D*F & 18.8 & 33.9 & 25.8 \\
\hline GLC $($ Euro per ton $)=\mathrm{C}+\mathrm{G}$ & 63.9 & 65.5 & 62.7 \\
\hline
\end{tabular}

Sources: Please see footnotes (from 20 to 26)

${ }^{\text {a }}$ Assumptions validated by railway and logistics experts within the SPECTRUM consortium

${ }^{\mathrm{b}}$ Based on public routing software calculation

${ }^{\mathrm{c}}$ Estimations based on figures from HEATCO [12]

${ }^{\mathrm{d}}$ Assumptions validated by railway and logistics experts within the SPECTRUM consortium

${ }^{\mathrm{e}}$ Calculated basing on the average speed and the distance

${ }^{\mathrm{f}}$ Calculated basing on the average speed and the distance

${ }^{\mathrm{g}}$ An average $2 \mathrm{~h}$ per stop is assumed

approach. The starting point of the IPA is the micro-level, i.e. the traffic flow on a particular route. In contrast the top-downapproach starts on a macro level, i.e. by country. The results are different, as the first approach provides marginal costs whereas the second one provides average noise costs. In particular, the marginal air pollution cost is defined as the cost due to an extra train. In this study, the IPA is used to calculate the marginal external costs of the extra SPECTRUM-train on three service areas, as shown in the Fig. 3.

The IPA bottom-up approach is also used for estimating the noise cost reduction.

Two main types of noise cost can be distinguished:

- Costs of annoyance;

- Health costs.

In fact, transport noise can cause not only discomfort or inconvenience, but also damage to physical health, including nervous stress reactions, such as change of heart beat

Table 5 User benefits of the SPECTRUM project per service area (Euro per ton)

\begin{tabular}{llcl}
\hline & Service area 1 & Service area 2 & Service area 3 \\
\hline $\begin{array}{c}\text { User benefit per ton } \\
\text { (existing rail traffic) }\end{array}$ & 0.38 & 2.39 & 1.35 \\
$\begin{array}{c}\text { User benefit per ton } \\
\text { (shifted traffic) }\end{array}$ & 7.12 & 7.19 & 1.12 \\
$\begin{array}{c}\text { User benefit per ton } \\
\text { (new traffic) }\end{array}$ & 69.43 & 114.81 & 62.77 \\
\hline
\end{tabular}

Source: Authors' elaborations frequency, increase of blood pressure and hormonal changes, increased risk of cardiovascular diseases, decreased sleep quality and hearing damage.

Key cost drivers for noise costs are:

- Time of the day: people are more sensitive to noise during night time than day time, hence the marginal costs will be higher at night;

- Reception density near to the source: gives an indication of the population exposed to the noise,

- Existing noise levels: due to the logarithmic noise characteristics, the marginal costs depend strictly on the existing noise levels, i.e. on the volume, mix and speed of the existing traffic.

The marginal external noise cost $\mathrm{T}$ is calculated as follows [2]:

$T=\sum_{L} C(L) \times N(L) \times \Delta L$

Where $\mathrm{C}(\mathrm{L})$ is the cost associated with the noise level $\mathrm{L}$, $\mathrm{N}(\mathrm{L})$ the total number of people exposed in the noise interval centred around $\mathrm{L}$ and $\Delta \mathrm{L}$ the percentage change in sound level due to the extra train.

Thus, the specific marginal cost $t$, expressed in Euro/(ton*km), is equal to:

$t=T /(W \times D)$

Where $\mathrm{W}$ is the total carried payload and $\mathrm{D}$ the total distance covered. 
Table 6 Type of SPECTRUM traffic in 2030 and 2044 (ton)

\begin{tabular}{|c|c|c|c|c|c|c|}
\hline & \multicolumn{2}{|c|}{ Service area 1} & \multicolumn{2}{|c|}{ Service area 2} & \multicolumn{2}{|c|}{ Service area 3} \\
\hline & 2030 & 2044 & 2030 & 2044 & 2030 & 2044 \\
\hline Existing rail traffic (ton) & 439,394 & 523,199 & 833,828 & 993,181 & 107,246 & 125,822 \\
\hline Shifted traffic (ton) & 145,455 & 175,342 & 229,970 & 273,349 & 14,493 & 14,029 \\
\hline New traffic (ton) & 0 & 5 & 14,837 & 22,820 & - & 2723 \\
\hline
\end{tabular}

Source: Results from the TRANSTOOLS model
The noise level has been calculated following the procedure proposed in the UK standards $[1,9]$. The procedure consists of the following six stages:

- Stage 1 (Segments): Divide railway into homogeneous segments in order to ensure that the noise variation within each element is less than $2 \mathrm{~dB}(\mathrm{~A})$. Hence, the following categories have been considered:

- Type of environment: urban/rural;

- Number of tracks: single/double track railway;

- Type of support: ballast with concrete sleepers/bridges;

- Presence of points $(\mathrm{S} \& \mathrm{C})$ to model a station.

- Stage 2 (Reference SEL): Calculate the reference noise level SELref at a reference distance of $25 \mathrm{~m}$ as:

$S E L_{r e f}=31.2+20 \log _{10} V$

Where $\mathrm{V}$ is the travelling speed. Afterwards, the corrections for vehicle type, number of vehicles and track structure are applied in order to take in account the length of the train, the type of track and the track support system. In particular, considering the list reported in AEAT [1], the correction for the KQA loaded wagon has been used due to the characteristics similar to the SPECTRUM vehicle.

- Stage 3 (Propagation): Apply the corrections for the distance of reception point from the track, ground and air absorption, effect of screening and angle of view at the reception point. Distance of reception point: two adjustments have been made in order to refine the calculations. In the first one, a $250 \mathrm{~m}$ wide band on each side of the railway has been considered with an equivalent noise level equal to $85 \%$ of the maximum level. In the second

Table 7 Unit external costs of air pollution and climate change for the SPECTRUM service (Euro cent is abbreviated as €ct)

\begin{tabular}{llll}
\hline External cost & Service area 1 & Service area 2 & Service area 3 \\
\hline Air pollution & $0.045 € \mathrm{ct} / \mathrm{tkm}$ & $0.011 € \mathrm{ct} / \mathrm{tkm}$ & $0.252 € \mathrm{ct} / \mathrm{tkm}$ \\
Climate change & $0.021 € \mathrm{ct} / \mathrm{km}$ & $0.019 € \mathrm{ct} / \mathrm{km}$ & $0.485 € \mathrm{ct} / \mathrm{tkm}$ \\
\hline
\end{tabular}

Source: Authors' elaborations adjustment three bands corresponding to three noise levels have been calculated on either side of the railway.

- Stage 4 (Reflection): Apply the corrections for reflection effects, which include façade effects and opposite façade effects.

- Stage 5 (LAeq): The resulting SEL values after the corrections determined at Stage 3 and Stage 4 are converted to LAeq values taking in account both the time period and the number of trains.

In SPECTRUM, the shift of high volume low density goods to rail modifies external impacts in terms of safety. This externality derives from both an improvement of the quality of rail logistics and the differential safety connected to the shift from road (or other modes) to rail transport. There is a total marginal accident cost (internal plus external) associated with the consequences of a vehicle entering a traffic flow because it exposes the user to the average accident risk in that transport mode. It also increases or decreases the accident risk for others of the same mode and may influence the accident risk of other transport modes.

The cost of an accident, ex ante, includes three components:

a) willingness-to-pay (WTP) for safety on part of those travelling in a particular mode exposed to the risk;

b) WTP on the part of relatives and friends of the person;

c) costs on the part of the rest of the society.

The social costs included in component $c$ are to a large extent internalised by insurance premiums paid by the vehicle owner. The user internalises in his decision to do a journey the risk he exposes himself to, valued as his WTP. The remaining cost, the marginal external cost, consists of three components:

I. System externalities, which is the expected accident cost to the rest of the society $(c)$ when the user exposes himself to risk $(r)$ by entering into the traffic flow and includes mainly medical and hospital costs.

Table 8 Unit external cost of noise for the SPECTRUM service

\begin{tabular}{llll}
\hline External cost & Service area 1 & Service area 2 & Service area 3 \\
\hline Noise & $0.035 € \mathrm{ct} / \mathrm{km}$ & $0.022 € \mathrm{ct} / \mathrm{tkm}$ & $0.028 € \mathrm{ct} / \mathrm{tkm}$ \\
\hline
\end{tabular}

Source: Authors' elaborations 
Table 9 Unit external costs per category (euro per $1000 \mathrm{tkm}$ )

\begin{tabular}{|c|c|c|c|c|c|c|c|}
\hline Euro per $1000 \mathrm{tkm}$ & $\begin{array}{l}\text { Road } \\
\text { (service area 1) }\end{array}$ & $\begin{array}{l}\text { Road } \\
\text { (Service Area 2) }\end{array}$ & $\begin{array}{l}\text { Road } \\
\text { (Service Area 3) }\end{array}$ & $\begin{array}{l}\text { SPECTRUM rail } \\
\text { (Service area 1) }\end{array}$ & $\begin{array}{l}\text { SPECTRUM rail } \\
\text { (Service area 2) }\end{array}$ & $\begin{array}{l}\text { SPECTRUM rail } \\
\text { (Service area 3) }\end{array}$ & Regular Rail \\
\hline Accidents & 17,00 & 17,00 & 17,00 & 0,15 & 0,03 & 0,09 & 0,20 \\
\hline Air pollution & 9,21 & 2,93 & 8,77 & 0,45 & 0,11 & 2,52 & 1,70 \\
\hline $\begin{array}{l}\text { Climate change } \\
\text { (average) }\end{array}$ & 4,89 & 6,26 & 9,16 & 0,21 & 0,19 & 4,85 & 2,30 \\
\hline Noise & 2,50 & 2,50 & 2,50 & 0,35 & 0,22 & 0,28 & 1,00 \\
\hline $\begin{array}{l}\text { Up Down stream } \\
\text { Processes }\end{array}$ & 3,70 & 3,70 & 3,70 & 4,75 & 4,75 & 4,75 & 4,75 \\
\hline Nature and landscape & 0,70 & 0,70 & 0,70 & - & - & - & - \\
\hline Biodiversity losses & 0,50 & 0,50 & 0,50 & - & - & - & - \\
\hline $\begin{array}{l}\text { Soil and water } \\
\text { pollution }\end{array}$ & 1,00 & 1,00 & 1,00 & 0,40 & 0,40 & 0,40 & 0,40 \\
\hline Urban effects & 0,90 & 0,90 & 0,90 & 0,10 & 0,10 & 0,10 & 0,10 \\
\hline Congestion & 28,50 & 28,50 & 28,50 & - & - & - & - \\
\hline Total externalities & 68,89 & 47,19 & 72,73 & 6,40 & 5,81 & 12,99 & 10,45 \\
\hline
\end{tabular}

Sources: For accidents, air pollution, climate change and noise: authors' elaborations. for other categories: [11]).

System externalities $=\boldsymbol{c} \times \boldsymbol{r}$

II. Traffic volume externalities, which sums the WTP of vehicle users $(a)$, relatives and friends $(b)$, and costs for the rest of society $(c)$ related to the increase or decrease in the accident risk for all other users of the same mode, caused by an additional user.

Table 10 CBA results

\begin{tabular}{llll}
\hline Euro millions (NPV) & Service area 1 & Service area 2 & Service area 3 \\
\hline Investment costs $^{\mathrm{a}}$ & 3,3 & 5,6 & 2,2 \\
Development costs & 35,5 & 54,9 & 4,0 \\
Operating costs & 11,7 & 38,4 & 4,9 \\
Total costs & 50,5 & 98,9 & 11,1 \\
& & & \\
Internal benefits & 16,7 & 73,1 & 2,4 \\
$\quad$ users' surplus) & & & \\
External benefits & 77,8 & 123,3 & 3,8 \\
$\quad$ (reduction of & & & \\
$\quad$ external costs) & & & \\
Total benefits & 94,5 & 196,4 & 6,2 \\
& & & \\
Total NPV & 43,9 & 97,5 & 4,9 \\
ERR & $14 \%$ & $18 \%$ & n.c. \\
BCR & 1,9 & 2,0 & 0,6 \\
\hline
\end{tabular}

Source: Authors' elaborations

${ }^{a}$ Financial costs for investment in terminals (necessary adjustments of the intermodal terminals for the implementation of the container-mover technology): investment in terminal infrastructure: $300.000 €$ per terminal; investment in terminal equipment: $1.000 .000 €$ per terminal. Conversion factors are applied
Traffic volume externalities $=(\boldsymbol{a}+\boldsymbol{b}+\boldsymbol{c}) \times \boldsymbol{r} \times \boldsymbol{E}_{\boldsymbol{r} Q}$

where $E_{r Q}$ is risk elasticity for occupants of the vehicle.

III. Traffic category externalities, which is the WTP of the vehicle users $(a)$, relatives and friends $(b)$, and costs for the rest of society $(c)$ related to the changed accident risk in other modes of transport.

Traffic volume externalities $=(\boldsymbol{a}+\boldsymbol{b}+\boldsymbol{c}) \times \boldsymbol{r}^{\prime} \times\left(1+\boldsymbol{E}_{\boldsymbol{r}^{\prime} \boldsymbol{Q}}\right)$

where $r^{\prime}$ is the risk non-occupants are exposed to and $E_{r^{\prime}} Q$ is risk elasticity for non-occupants of the vehicle.

According to the countries included in different service areas, weighted marginal external accident costs are calculated for each Service Area. Weighted marginal external accident costs can be expressed as

Weighted Marginal External Accident Cost $=\frac{\sum_{\mathrm{i}} \text { MEAC }_{\mathrm{i}} \times \text { Distance }_{\mathrm{i}}}{\sum \text { Distance }}$

where $M E A C$ is the marginal external accident cost for the country, based on RECORDIT figures ${ }^{8}$ (adjusted to 2012 price levels).

For Service Area 1 the figure is 0.04 Euro per train-km, for Service Area 2 it is 0.01 Euro per train-km and for Service Area 3 it is 0.03 Euro per train-km.

For other types of externalities the SPECTRUM service is assumed to not yield different impacts than the regular rail services, therefore the standard unit parameters of rail freight transport have been applied (area-specific where available) for

\footnotetext{
${ }^{8}$ Baccelli, O. et al., [3].
} 
Fig. 2 Logical scheme for the quantification of external effects, Source: The authors
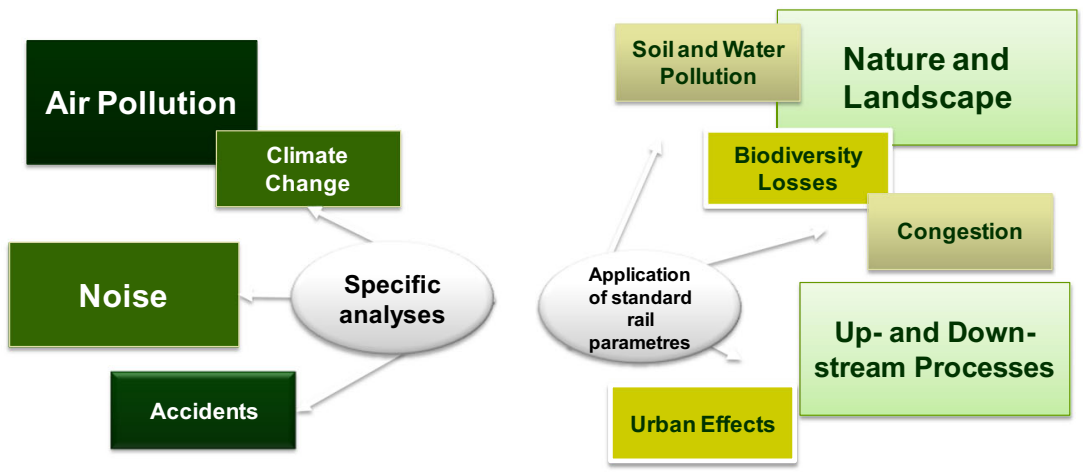

comparing the SPECTRUM impact to the all road situation. Such externalities are the following:

- Up- and down-stream processes

- Nature and landscape

- Biodiversity losses

- Soil and water pollution

- Urban effects

- Congestion

according to the mentioned "EC Handbook" on external costs [27].

The final unit values for all externalities considered are presented in the following table.

Fig. 3 IPA for the calculation of air pollution costs in SPECTRUM, Source: The Authors

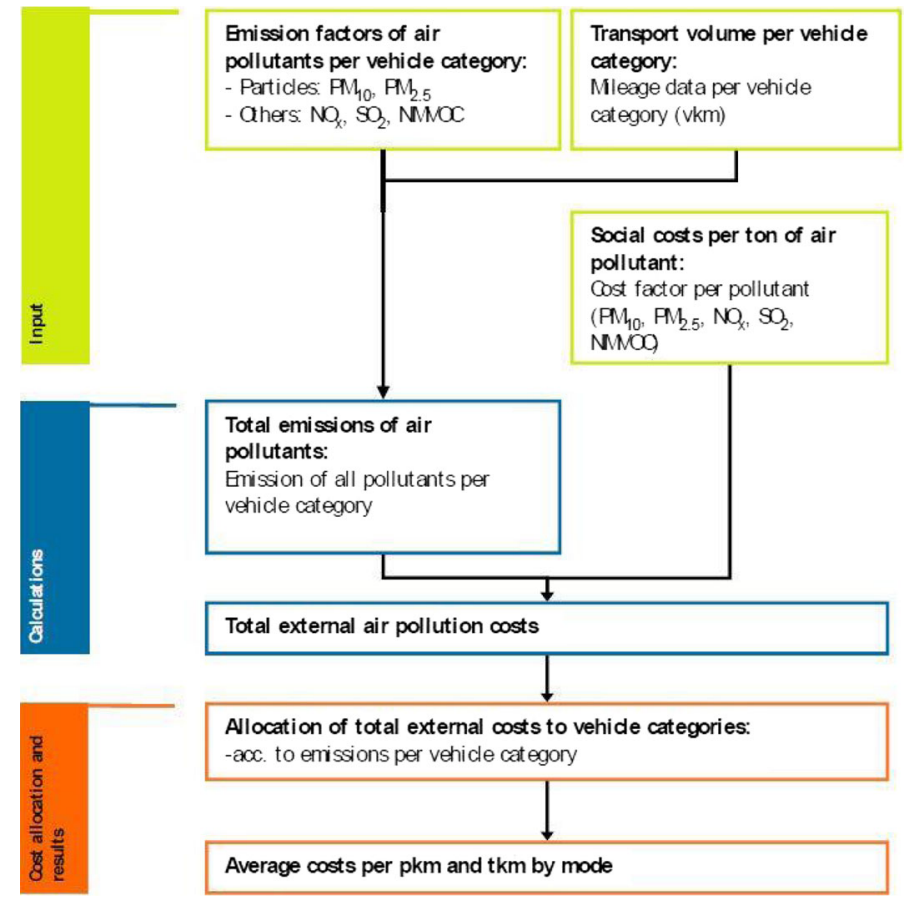

Air Pollution Costs $=$ Energy Consumption (kwh or kg) $\mathbf{X}$

Emission Factors for Production and Operation (g/kwh or g/kg) X

Social Costs Factors (€/ton) 
reliability as an update to their Guide so that it may be considered in future works similar to those presented in this paper.

\section{Results}

The overall results of the CBAs are positive, except for Service Area 3, in terms of NPV and the other CBA indicators. The high costs of investment are compensated by the benefits, thanks to the relevant modal shift achieved and to the fact that - from the society point of view - the relevant operating costs are almost completely compensated by the operating costs saved for alternative services (regular rail or road, see 3.1 and 3.2). In Service Area 3, instead, the modal shift is not relevant enough to generate the necessary amount of benefits to compensate for total costs. The following table sums up the NPVs of costs and benefits, as well as the CBA indicators, for each Service Area analyzed.

\section{Conclusions}

The adapted methodology presented in this paper is still considered to be consistent with the European Commission's guidelines on the matter and has proven capable of representing the multiple effects as a result of the theoretical introduction of an innovative rail service in the freight transport sector, accounting for the differential impacts as compared to the baseline scenario solutions (all-road solutions and regular rail solutions).

The estimation of costs derived from the application of standard conversion factors to the financial costs (whose calculation has been developed as part of previous research).

Tariff revenues were not taken into account as they are considered mere transfers of money between different operators involved in the sector; however unit tariffs have been considered as one of the elements that contribute to the estimation of GLCs, which are a proxy for quantifying internal benefits (in terms of user's surplus).

The particular parts of the CBA methodology that had to be adapted for the purpose of this evaluation were:

- the estimation of ad hoc unit parameters for the external costs involving emissions, noise and accidents (the EC guidelines provide parameters for comparing road and rail transports, but since the SPECTRUM solution is novel, new parameters were needed and therefore estimated);

- an ad hoc approach for using GLC as proxies of users' surplus in a scenario where the introduction of the innovative service modifies the modal split of freight transport between three types of solutions (EC Guidelines do not provide specific details for projects whose outcome is a three-way choice for freight transport).

The logical articulation of the analysis is flexible and the two above mentioned estimation schemes can be applied to other service areas as well as for the evaluation of other types of freight transport services, provided that some unit data can be retrieved, which pertain to site-specific cost of infrastructures, average speeds and rates of different transport solutions, costs of personnel and other operating costs, and site-specific analyses carried out in order to estimate relevant unit external cost parameters.

It can be noted that conventional freight trains can use SPECTRUM terminals but not vice versa, that is why some investment cost is taken into account for upgrading terminals in order to run the SPECTRUM solution.

Open Access This article is distributed under the terms of the Creative Commons Attribution 4.0 International License (http:// creativecommons.org/licenses/by/4.0/), which permits unrestricted use, distribution, and reproduction in any medium, provided you give appropriate credit to the original author(s) and the source, provide a link to the Creative Commons license, and indicate if changes were made.

\section{References}

1. AEAT (2007) Additional railway noise source terms for "Calculation of Railway Noise 1995". Department for Environment, Food and Rural Affairs (DEFRA), London

2. Andersson H, Ögren M (2007) Noise charges in railway infrastructure: a pricing schedule based on the marginal cost principle. Transp Policy 14(3):204-213

3. Baccelli $\mathrm{O}$ et al. (2001) External cost calculation for selected corridors, RECORDIT (Real Cost Reduction of Door-to-door Intermodal Transport) Project Deliverable 4. European Commission, Brussels

4. Braekers K, Janssens GK, Caris A (2009), Review on the comparison of external costs of intermodal transport and unimodal road transport, In Proceedings of the BIVEC-GIBET Transportation Research Day (pp. 875-890). BIVEC-GIBET Transportation Research Day

5. CER, (2008), European railway legislation handbook, DVV Media Group GmbH Eurail Press, Hamburg, pp-25-26.

6. Coto-Millan P, Inglada V, Rey B (2007) Effects of network economies in high-speed rail: the Spanish case Ann. Reg Sci 41:911-925

7. CREAM (2015), CREAM project website - http://www.creamproject.eu/home/service.php, last retrieved 01/06/2015

8. De Rus G, Inglada V (1997) Cost-benefit analysis of the high-speed train in Spain. Ann Reg Sci 31:175-188

9. Department of Transport (1995), Calculation of railway noise. HMSO, London

10. European Commission, (2008), Guide to cost-benefit analysis of investment projects. Structural Funds, Cohesion Fund and Instrument for Pre-Accession, 2008

11. European Commission (2011) Transport White Paper - Roadmap to a Single European Transport Area - Towards a competitive and resource efficient transport system. European Commission, Brussels 
12. HEATCO, (2005) Developing Harmonised European Approaches for Transport Costing and Project Assessment, IER Stuttgart

13. Hilmola O-P (2008) Railway Wagon Market Analysis and New Multi-purpose Wagon Solution for Freight Transports - Finnish Manufacturing Perspective Railway Wagon Market Analysis and New Multi- Purpose Wagon Solution for Freight Transports e Finnish Manufacturing Perspective, Research Report 194, European Union and TEKES

14. Islam DMZ, Eidhammer O (2015). Advances in the competitiveness of pan-European rail freight services: findings from a case study. R \& D Management

15. Jackson R, Islam $\mathrm{D}$, Zunder $\mathrm{T}$, Schoemaker J, Dasburg $\mathrm{N}$, (2014) A market analysis of the low density high value goods flows in Europe. Sel. Proc. 13th World Conf. Transp Res (WCTR). 2014, Rio Janeiro COPPE - Fed. Univ. Rio Janeiro, Brazil, pp. 1-12

16. Johnson K (2012). European Rail Freight Corridor: Linking UK and Continental Europe

17. Krüger NA, Vierth I (2015) Precautionary and operational costs of freight train delays: a case study of a Swedish grocery company. Eur Transp Res Rev 7:6

18. Mackie PJ, (2010), Cost-benefit analysis in transport: a UK perspective. Discussion Paper 16), Mexico, 26-27

19. Mackie PJ, Preston JM (1998) Twenty-one sources of error and bias in transport project appraisal. Transp Policy 5(1):1-7
20. Maibach M, Schreyer C, Sutter D, van Essen H P, Boon B H, Smokers R, Bak M (2008). Handbook on estimation of external costs in the transport sector Produced within the study. IMPACT. Delft

21. Ravasio M, Senn L, (2001), Investire in infrastrutture. La convenienza economica dei progetti di trasporto, Egea, Milano.

22. RETRACK, 2013, REorganization of Transport Networks by advanced Rail freight Concepts, project website http://www.retrack. eu/, last retrieved 01/06/2015

23. SPECTRUM, (2013), SPECTRUM - Solutions and Processes to Enhance the Competitiveness of freight Transport by Rail in Unexploited Markets Deliverable 2.2 - Capacity management to meet the demands of LDHV goods transportation by rail

24. SPECTRUM, (2015), Spectrum - Solutions and Processes to Enhance the Competitiveness of freight Transport by Rail in Unexploited Markets, project website- http://www.spectrumrail.info/

25. Stead D (2003) The External Costs of Transport and Electricity Generation. Ejtir 3(3):317-320

26. Törnquist J, Gustafsson I (2004) Perceived benefits of improved information exchange - a Case Study on Rail and Intermodal Transports. Res Transp Econ 8(04):415-440. doi:10.1016/S0739-8859(04)08018-7

27. Van Essen H, Schroten A, Otten M, Sutter D, Schreyer C, Zandonella R, Maibach M, Doll C (2011). External Costs of Transport in Europe Update Study for 2008. CE Delft, INFRAS, Fraunhofer ISI. Retrieved from http://ecocalc-test.ecotransit.org/CE_Delft_4215_External_ Costs_of Transport in Europe def.pdf 